DOI: 10.12731/2658-6649-2019-11-5-2-50-55

УДК 616.24-007-06; 616.12-008.331.1-06

\title{
ОСОБЕННОСТИ ПСИХОЛОГИЧЕСКОГО ПРОФИЛЯ БОЛЬНЫХ С ХРОНИЧЕСКОЙ ОБСТРУКТИВНОЙ БОЛЕЗНЬЮ ЛЕГКИХ В УСЛОВИЯХ КОМОРБИДНОСТИ
}

\author{
Козлов Е.В., Яскевич Р.А.
}

Изучены особенности психологического профиля 65 больных хронической обструктивной болезнью легких (ХОБЛ). Из них у $44-c$ коморбидным течением ХОБЛ и артериальной гипертонии (АГ) и у $21-c$ изолированно протекающей ХОБЛ. Использовался сокращенный многофакторный опросник личности (СМОЛ). Анализ показал, что что более половины пациентов 1-й и 2-й группы имели признаки выраженной соииально-психологической дезадаптации, при этом достоверно чаще встречались у пациентов в условиях коморбидности.

Ключевые слова: хроническая обструктивная болезнь легких; артериальная гипертония; психологический профиль.

\section{FEATURES OF THE PSYCHOLOGICAL PROFILE OF PATIENTS WITH CHRONIC OBSTRUCTIVE LUNG DISEASE IN THE CONDITIONS OF COMORBIDITY}

\author{
Kozlov E.V., Yaskevich R.A.
}

The analysis of indicators of the psychological state of 65 patients with chronic obstructive pulmonary disease (COPD) was carried out. Of these, 44 had a comorbid course of COPD and arterial hypertension (AH) and 21 had a COPD that was isolated in isolation. Used abbreviated multivariate questionnaire of personality. The analysis showed that more than half of the patients of the 1 and 2 groups had signs of pronounced socio-psychological maladjustment, while they were significantly more frequent in patients under comorbid conditions.

Keywords: Chronic obstructive pulmonary disease; hypertension; psychological profile. 


\section{Введение}

В последнее время значительное количество проведенных исследований в различных областях здравоохранения подтверждают актуальность изучения психологических особенностей и качества жизни [2, c. 24,3 , с. $10,7$, c. 64,8, с. 2$]$ в том числе в пульмонологии, особенно у больных с хроническими нарушениями бронхиальной проходимости [5 c. 6]. Рост заболеваемости ХОБЛ во всем мире, определил отношение к этой патологии как к важнейшей медико-биологической и социальной проблеме современного здравоохранения [1, с. 92]. Сердечно-сосудистые заболевания являются одними из самых серьезных патологических состояний, сосуществующих с ХОБЛ [4, с. 180, 6, с. 3]. В то же время аспекты влияния АГ на психологическое состояние у больных ХОБЛ с АГ изучены недостаточно.

\section{Цель}

Изучить особенности психологического профиля у больных с ХОБЛ в условиях коморбидности с АГ.

\section{Материалы и методы исследования}

Изучение особенностей психологического профиля было проведено у 65 пациентов мужского пола с ХОБЛ, из которых 44 человека страдали АГ (2-я группа). Группу контроля составили 32 чел. с АГ без ХОБЛ (3-я группа). Оценка психологического профиля личности больных проводилась с помощью сокращенного многофакторного опросника личности (СМОЛ), разработанного на основе Миннесотского многопрофильного опросника личности (MМPI).

\section{Результаты и обсуждение}

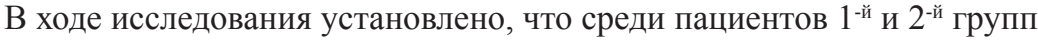
статистически значимых отличий по шкалам теста СМОЛ получено не

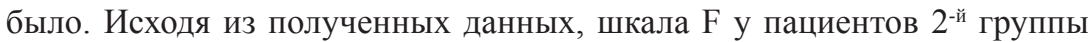
превышает шкалы L и K, что говорит о склонности данных больных к усугублению собственных проблем и слишком критично относиться к себе.

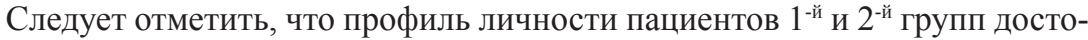
верно отличается от обследуемых $3^{-и ̆}$ группы, при этом ведущими шкалами лиц, страдающих ХОБЛ, оказались шкалы ипохондрии, тревоги и депрессии, демонстративности, психастении и аутизма. Полученные результаты в Т-баллах характеризуют данных больных беспокойством о состоянии своего здоровья, то есть выраженным ипохондрическим синдромом, од- 
новременно с этим они склонны к самообвинению, поиску проблем внутри себя, ограничению собственных потребностей, повышению уровня тревожно-депрессивных расстройств, а также склонны к невротическим защитным реакциям конверсионного типа («все проблемы разрешаются уходом в болезнь»). Кроме того, среди пациентов исследуемых групп отмечаются низкие значения по шкале ригидность, что может отражать недоверчивость и осторожность исследуемых пациентов. Повышение по шкале 7, 8 и тенденция к снижению по шкале 9 в данных группах в совокупности означает наличие депрессивных переживаний, а также снижение активности и недостаточную оценку собственных возможностей. Анализ индивидуальных профилей СМОЛ показал, что более, чем у половины больных в каждой из исследуемых групп отмечаются признаки социально-психологической дезадаптации, а именно, 70,4\% $1^{- \text {й }}$ группы, 86,8\% $2^{- \text {-й }}$ группы и $59 \% 3^{\text {-й }}$ группы. Особое внимание обращает на себя тот факт,

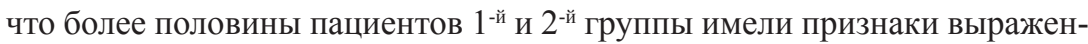
ной социально-психологической дезадаптации, при этом достоверно чаще встречались у пациентов при коморбидности данных патологий.

\section{Заключение}

Анализ индивидуальных профилей СМОЛ показал необходимость психологической коррекции пациентов с ХОБЛ для предупреждения развития депрессивных, тревожных и ипохондрических расстройств. Изучение профиля личности в обследуемых группах позволило выявить некоторые психологические особенности, что необходимо учитывать при проведении дополнительной психотропной терапии и психотерапии.

\section{Сиисок литературы}

1. Глобальная стратегия диагностики, лечения и профилактики хронической обструктивной болезни легких (пересмотр 2014 г.) / Пер. с англ. под ред. А.С. Белевского. М.: Российское респираторное общество, 2014. 92 с.

2. Давыдов Е.Л., Ульянова И.О. Медико-социальные аспекты больных артериальной гипертонией в пожилом возрасте // Клиническая геронтология. 2016. Т. 22, № 9-10. С. 24-25.

3. Деревянных Е.В., Балашова Н.А., Яскевич Р.А., Москаленко О.Л. Частота и выраженность тревожно-депрессивных нарушений у студентов медицинского вуза // В мире научных открытий. 2017. Т. 9. № 1. С. 10-28.

4. Козлов Е.В., Деревянных Е.В., Балашова Н.А. и др. Хроническая обструктивная болезнь легких как социально-экономическое бремя взрослого на- 
селения (научный обзор) // В мире научных открытий. 2018. Т. 10, № 3. C. $180-199$.

5. Козлов Е.В., Петрова М.М., Харьков Е.И. Качество жизни у больных хронической обструктивной болезнью легких в сочетании с артериальной гипертонией // Забайкальский медицинский вестник. 2014. №4. С. 6-13.

6. Разумов А.Н., Бобровницкий И.П., Колесникова И.В. и др. Влияние электромагнитных полей на тонус церебральных сосудов и артериальное давление // Вопросы курортологии, физиотерапии и лечебной физической культуры. 2006. № 2. С. 3-5.

7. Ремизов Е.В., Давыдов Е.Л., Корепина Т.В. Проблемы качества жизни пациентов старших возрастных групп с артериальной гипертонией // Военно-медицинский журнал. 2012. № 5. С. 64.

8. Филимонова Л.А., Борисенко Н.А., Алексеев И.А. и др. Мониторинг качества жизни у пациентов артериальной гипертонии старших возрастных групп // Современные проблемы науки и образования. 2017. № 1. С. 2.

\section{References}

1. Global naya strategiya diagnostiki, lecheniya i profilaktiki xronicheskoj obstruktivnoj bolezni legkix (peresmotr 2014 g.) [The global strategy for the diagnosis, treatment and prevention of chronic obstructive pulmonary disease (revision 2014)] / Per. s angl. pod red. A.S. Belevskogo. M.: Russian Respiratory Society, 2014. 923.

2. Davy`dov E.L., Ul`yanova I.O. Mediko-social`ny`e aspekty` bol’ny`x arterial'noj gipertoniej v pozhilom vozraste [Medical and social aspects of patients with arterial hypertension in old age]. Klinicheskaya gerontologiya [Clinical gerontology]. 2016. V. 22, № 9-10, pp. 24-25.

3. Derevyannyh E.V., Balashova N.A., YAskevich R.A., Moskalenko O.L. CHastota i vyrazhennost' trevozhno-depressivnyh narushenij u studentov medicinskogo vuza [The frequency and severity of anxiety-depressive disorders in medical students]. V mire nauchnyh otkrytij [In the world of scientific discoveries]. 2017. V. 9. № 1, pp. 10-28.

4. Kozlov E.V., Derevyanny`x E.V., Balashova N.A. et al. Xronicheskaya obstruktivnaya bolezn' legkix kak social 'no-e'konomicheskoe bremya vzroslogo naseleniya (nauchny`j obzor) [Chronic obstructive pulmonary disease as a socio-economic burden of the adult population (scientific review)]. Vmire nauchny'x otkry 'tij [In the world of scientific discoveries]. 2018. V. 10, № 3, pp. 180-199.

5. Kozlov E.V., Petrova M.M., Xar kov E.I. Kachestvo zhizni u bol’ny`x xronicheskoj obstruktivnoj bolezn 'yu legkix v sochetanii s arterial`noj gipertoniej 
[Quality of life in patients with chronic obstructive pulmonary disease in combination with arterial hypertension]. Zabajkal skij medicinskij vestnik [Transbaikalian Medical Journal]. 2014. № 4, pp. 6-13.

6. Razumov A.N., Bobrovnickij I.P., Kolesnikova I.V. i dr. Vliyanie elektromagnitnyh polej na tonus cerebral'nyh sosudov i arterial'noe davlenie [The influence of electromagnetic fields on the tone of cerebral vessels and blood pressure]. Voprosy kurortologii, fizioterapii i lechebnoj fizicheskoj kul'tury [Questions of balneology, physiotherapy and physical culture]. 2006. № 2, pp. 3-5.

7. Remizov E.V., Davydov E.L., Korepina T.V. Problemy kachestva zhizni pacientov starshih vozrastnyh grupp s arterial'noj gipertoniej [Problems of quality of life of patients in older age groups with arterial hypertension]. Voenno-medicinskij zhurnal [Military Medical Journal]. 2012. № 5. P. 64.

8. Filimonova L.A., Borisenko N.A., Alekseev I.A. et al. Monitoring kachestva zhizni u pacientov arterial'noj gipertonii starshix vozrastny`x grupp [Monitoring the quality of life in patients with arterial hypertension in older age groups]. Sovremenny 'e problemy' nauki i obrazovaniya [Modern problems of science and education]. 2017. № 1. P. 2.

\section{ДАННЫЕ ОБ АВТОРАХ}

Козлов Евгений Вячеславович, доцент кафедры пропедевтики внутренних болезней и терапии, заведующий пульмонологическим отделением, кандидат медицинских наук

ГБОУ ВПО «КрасГМУ им. проф. Ф.В. Войно-Ясенецкого» МЗ РФ; КГБУЗ «Красноярская межрайонная клиническая больница скорой медищинской помощии имени Н.С. Карповича»

ул. Партизана Железняка, 1а, г. Красноярск, 660022, Российская Федерачия; ул. Курчатова, 17, г. Красноярск, 660062, Российская Федераиия kev-pulmonolog@mail.ru

Яскевич Роман Анатольевич, доцент кафедры пропедевтики внутренних болезней и терапии, ведущий научный сотрудник, кандидат медицинских наук, доцент

ГБОУ ВПО «КрасГМУ им. проф. Ф.В. Войно-Ясенецкого» МЗ РФ; Федеральное государственное бюджетное научное учреждение «Научно-исследовательский институт медицинских проблем Севера» 
ул. Партизана Железняка, 1а, г. Красноярск, 660022, Российская Федераџия; ул. Партизана Железняка, 32, г. Красноярск, 660022, Российская Федераиия

cardio@impn.ru

\section{DATA ABOUT THE AUTHORS}

Kozlov Evgeny Vyacheslavovich, associate professor at department of propedeutics of internal diseases and therapy, head of pulmonology department, candidate of medical science

Krasnoyarsk State Medical University named after Professor V.F. VoinoYasenetzkiy; Krasnoyarsk Interdistrict Clinical Hospital of Emergency Medical Care

1a, P. Zheleznyaka St., Krasnoyarsk, 660022, Russian Federation; 17, Kurchatov St., Krasnoyarsk, 660062, Russian Federation kev-pulmonolog@mail.ru

Yaskevich Roman Anatolyevich, associate professor at department of propedeutics of internal diseases and therapy, leading researcher, candidate of medical science, docent

Krasnoyarsk State Medical University named after Professor V.F. Voino-Yasenetzkiy; Scientific Research Institute of medical problems of the North

1a, P. Zheleznyaka St., Krasnoyarsk, 660022, Russian Federation; 3g, P. Zheleznyaka St., Krasnoyarsk, 660022, Russian Federation cardio@impn.ru 